\title{
Prevalence and related factors of internet addiction among undergraduate university students, Northeastern Ethiopia. A community university- based cross-sectional study
}

Yosef Zenebe ( $\nabla$ yosef.zenebe79@gmail.com )

Wollo University https://orcid.org/0000-0002-0138-6588

Kunuya Kunno

Wollo University

Meseret Mekonnen

Wollo University

Ajebush Bewuket

Wollo University

Mengesha Birkie

Wollo University

Mogesie Necho

Wollo University

Muhammed Seid

Wollo University

Million Tsegaw

Wollo University

Baye Akele

Wollo University

Research

Keywords: Internet addiction, Prevalence, Mental distress, Dessie, Ethiopia

Posted Date: January 27th, 2020

DOI: https://doi.org/10.21203/rs.2.21929/v1

License: (c) (1) This work is licensed under a Creative Commons Attribution 4.0 International License.

Read Full License 


\section{Abstract}

Background: Globally, more than three billion persons using the Internet daily, with the common being youths and young persons. Internet addiction among university students in Ethiopia has not been studied. The current study aims to explore the magnitude and related factors of internet addiction among Wollo University students in Ethiopia.

Objectives: The main objective of this study was to assess the prevalence and related factors of internet addiction among Wollo University students, Northeast, Ethiopia, 2019.

Methods: A community university-based cross-sectional study was conducted among Wollo University students from April 10 to May 10, 2019, G.C. A total of six hundred three students were participated in the study using a pretested and self-administered structured questionnaire. The Young's Internet Addiction Test instrument was used to assess the level of internet addiction.

Results: Generally, the prevalence of internet addiction (IA) among the current internet users was $85 \%$ $(n=466)$ with $55.7 \%(n=305)$ mild internet addiction, $27.9 \%(n=153)$ moderate internet addiction and 1.5\% $(n=8)$ severe internet addiction. In multivariable logistic regression analysis, using the internet greater than five hours daily, having mental distress, playing online games, current khat chewing and current alcohol use were positively related to internet addiction. Using the internet for more than twelve months and using the internet by mobile internet were negatively related to internet addiction.

Conclusions: The current study documents a high prevalence of internet addiction among Wollo University students. Factors independently associated with internet addiction were using the internet greater than five hours daily, having mental distress, playing online games, current khat chewing and current alcohol use.

\section{Background}

Globally, more than three billion persons using the Internet daily (1), with the majority being youths and young persons (2). In the field of medicine and healthcare, it helps in the practice of evidence-based medicine, research and learning, access to medical and online databases, handling patients in remote areas, and academic and recreational purposes $(3,4)$. Relaxed access and social networking are two of the several aspects of the Internet development of addictive behavior(5). Internet addiction in puberty can negatively impact personality information and may negatively affect cognitive functioning, lead to poor academic performance and engagement in hazardous activities, and inculcate poor dietary habits (6). Problematic internet use is also related to anxiety and stress(7). It has been found that paranoid ideation, hostility, anxiety, depression, interpersonal sensitivity, and obsessive-compulsive average scores are higher in people with high internet addiction scores than those without internet addiction $(8,9)$.

College students are especially susceptible to developing a dependence on the Internet, more than most other segments of society. This can be qualified to numerous factors including the following: Availability 
of time; ease of use; unlimited access to the Internet; the psychological and developmental characteristics of young adulthood; limited or no parental supervision; an expectation of Internet/computer use covertly if not obviously, as some courses are Internet-dependent, from assignments and projects to link with peers and mentors; the Internet offering a way of escape from exam anxiety, age, making new friendships online, getting into relationships online, being sexual inactive, failure in academic performance, gender, low self-esteem, anxiety, depression, insomnia, attention deficient disorder and hyperactivity symptoms, smoking, visiting pornographic sites, playing online games and potential addictive personal habits of, drinking alcohol or coffee, and taking drugs, duration of internet use and mental distress (10-19).

Internet addiction is now becoming a serious mental health problem among Chinese adolescents. The researchers identified $10.6-13.6 \%$ of Chinese college students as Internet addicts $(20,21)$.A study conducted among Taiwan college students reported that the prevalence of Internet addiction was 15.3\% (18).

The prevalence of problematic internet use (PIU) was greater among university students. For instance, the prevalence was 36.9 to $81 \%$ in Malaysian medical students(22, 23), $16.8 \%$ in American medical students(11), 25.1\% in American community university students(24), 40.7\% in Iranian university students(25), 38.2-63.5\% IA in Japanese university students(15, 26), 16.8\% IA in Lebanon University students (11), 35.4\% IA in Nepal undergraduate students(17),40\% IA in Jordan University students (16),19.85-42\% IA in various parts of India $(12,14,19), 12 \%$ IA to $34.7 \%$ (PIU) in Greek University students (13), 1.6\% IA in Turkey students (27). Internet addiction among university students in Ethiopia has not been studied. The current study aims to explore the prevalence and related factors of internet addiction among Wollo University students in Ethiopia.

\section{Methods And Materials}

\section{Study area and period}

The study was done at Wollo University, Dessie campus that is found in South Wollo Zone, Amhara Regional State which is 401 kilometers far from Addis Ababa, North Ethiopia. It had 5 colleges and 2 schools and a total of 62 departments. The number of regular students in 2018/2019 G.C is 7248; among these 4009 are males and 3239 are females. The study was conducted from April 10 to May 10/ 2019 G.C.

\section{Sample size determination}

The sample size was determined using single population proportion formula, taking $50 \%$ prevalence of internet addiction with the following assumption: $95 \% \mathrm{Cl}, 5 \%$ margin of error, $10 \%$ non-response rate and a design effect of 1.5. So, the final sample size was 603 .

\section{Sampling technique and procedure}


A multistage cluster sampling was adopted for this study. In the first stage, by the use of the lottery method, two colleges (College of medicine and health sciences, and College of natural sciences), and one school (school of law) were selected. In the second stage, 18 departments were selected from the colleges and school. Students were selected proportionally from the given departments based on the number of students of a particular. A community university-based cross-sectional study was conducted among Wollo University students' age ranges from 18 to 30 years.

\section{Study instruments}

Self-administered, well-structured and organized English version questionnaire was disseminated to students and data were collected from the individual student. The questionnaire comprised six parts, the first part consisted of socio-demographic details, the second part consists of Young's Internet Addiction Test (YIAT). The Internet Addiction Test(28) is the most commonly used measure of Internet addiction(29). It includes 20 questions with a scoring of 1-5 for each question and a total maximum score of 100. Based on scoring subjects would be classified into normal users (0-30), mild (31-49), moderate (50-79) and severe (80-100) internet addiction groups. Mild addiction, moderate addiction, and severe addiction were categorized as having an internet addiction. YIAT20 showed that it is more reliable in University students. The Generally Cronbach a in the present study was 0.89 , the third part timerelated factors, the fourth part reasons for internet use, the fifth part psychoactive substance use-related factors and the last part mental health problem-related factors and it was assessed by Kesler10. The Kessler Psychological Distress Scale (K10)(30) is a simple measure of psychological distress. The K10 scale involves 10 questions about emotional states each with a five-level response scale. The measure can be used as a brief screen to identify levels of distress. Scores will range from 10 to 50 . A score under 20 is likely to be well, a score of 20-24 is likely to have a mild mental disorder, a score of 25-29 are likely to have a moderate mental disorder and a score of 30 and over are likely to have a severe mental disorder. Study participants with a score of 20 or more points on the Kesler-10 Likert scale were considered as having mental distress(31).

\section{Data quality control}

A structured self-administered questionnaire was developed in English and would be translated to Amharic language and again translated back into English to ensure consistency. Data collectors and supervisors would be trained for two days on the objective of the study, the content of the questionnaire and the data collection procedure. Data would be pretested on $5 \%$ of the total sample size outside the study area and based on feedback obtained from the pretest, the necessary modification would be done. During the study period, the collected data would be checked continuously daily for completeness by principal investigator and supervisor in the respective departments.

\section{Data processing and analysis}

Quantitative data would be cleaned, coded and entered into Epi-data 3.1 and exported to SPSS version 21 for analysis. Descriptive data would be presented by a table, graphs, charts, and means. Multicollinearity was checked by using standard error and there was no correlation between independent variables. The 
association between independent variables and internet addiction would be made using a binary logistic regression model and all independent variables having $p$-value $\leq 0.25$ would be included in multiple logistic regression models. A P-value less than 0.05 and Adjusted Odds Ratio (AOR) with $95 \%$ Confidence Interval $(\mathrm{Cl})$ not inclusive of one would be considered as statically significant and would be used to determine predictors of internet addiction in the final model. Hosmer-Lemeshow test was done to check model fitness and the model was fit.

\section{Results}

\section{Socio-demographic characteristics of study participants}

A total of 603 respondents were participated in this study, of them 548 providing information which makes a response rate of $90.9 \%$. However, fifty-five $(n=55)$ participants were excluded.

The mean age of the respondents was 21.4 (SD 1.8) years, ranging from 18 to 30 years, and also more than half of, $291(53.1 \%)$ of respondents were males. Likewise, $245(44.7 \%)$ of the respondents attending the place of worship daily. Many of the study participants had a practice of using the internet for more than twelve months, 321 (58.6\%). About 501 (91.4\%), 268 (48.9\%), 433 (79\%) were using the internet less than five hours per day, most common mode of internet access Wi-Fi and log in and off occasionally during the day respectively. The study participants with current khat use, current cigarette smoking, current alcohol use, and current cannabis use were $19.0 \%, 11.3 \%, 25.4 \%$; and $4.0 \%$ respectively. About $19.3 \%$ of the participants had mental distress (Table 1 ).

\section{Table 1: Sociodemographic characteristics of study participants Northeast, Ethiopia, $2019(n=548)$}




\begin{tabular}{|c|c|c|c|c|c|}
\hline \multirow{2}{*}{\multicolumn{2}{|c|}{ Variables }} & \multicolumn{2}{|c|}{ Internet addiction } & \multirow[t]{2}{*}{ Frequency } & \multirow[t]{2}{*}{ Percent } \\
\hline & & Yes; $N$ (\%) & No; $N(\%)$ & & \\
\hline \multirow[t]{2}{*}{$\overline{\mathrm{Age}}$} & Below mean & $171(83.4 \%)$ & $34(16.6 \%)$ & 205 & 37.4 \\
\hline & Above mean & $295(86.0 \%)$ & $48(14.0 \%)$ & 343 & 62.6 \\
\hline \multirow[t]{2}{*}{ Sex } & Male & $249(85.6 \%)$ & $42(14.4 \%)$ & 291 & 53.1 \\
\hline & Female & $217(84.4 \%)$ & $40(15.6 \%)$ & 257 & 46.9 \\
\hline \multirow{5}{*}{$\begin{array}{l}\text { Frequency of } \\
\text { attending a place of } \\
\text { Norship }\end{array}$} & Daily & $204(83.3 \%)$ & $41(16.7 \%)$ & 245 & 44.7 \\
\hline & 2-3 times per week. & $123(85.4 \%)$ & $21(14.6 \%)$ & 144 & 26.3 \\
\hline & Once a week. & $58(82.9 \%)$ & $12(17.1 \%)$ & 70 & 12.8 \\
\hline & Less than weekly. & $53(89.8 \%)$ & $6(10.2 \%)$ & 59 & 10.8 \\
\hline & Never & $28(93.3 \%)$ & $2(6.7 \%)$ & 30 & 5.5 \\
\hline \multirow{3}{*}{$\begin{array}{l}\text { nternet use } \\
\text { experience (in } \\
\text { nonths) }\end{array}$} & 0 to 6 months & $120(91.6 \%)$ & $11(8.4 \%)$ & 131 & 23.9 \\
\hline & 6 to 12 months & $76(79.2 \%)$ & $20(20.8 \%)$ & 96 & 17.5 \\
\hline & 12 or more months & $270(84.1 \%)$ & $51(15.9 \%)$ & 321 & 58.6 \\
\hline \multirow{2}{*}{$\begin{array}{l}\text { nternet use per day } \\
\text { in hours) }\end{array}$} & Less than 5 hours & $420(83.8 \%)$ & $81(16.2 \%)$ & 501 & 91.4 \\
\hline & $\begin{array}{l}\text { Greater than or equal } \\
\text { to } 5 \text { hours }\end{array}$ & $46(97.9 \%)$ & $1(2.1 \%)$ & 47 & 8.6 \\
\hline \multirow{4}{*}{$\begin{array}{l}\text { The most common } \\
\text { node of Internet } \\
\text { tccess }\end{array}$} & $\mathrm{Wi}-\mathrm{Fi}$ & $230(85.8 \%)$ & $38(14.2 \%)$ & 268 & 48.9 \\
\hline & Broadband & $14(87.5 \%)$ & $2(12.5 \%)$ & 16 & 2.9 \\
\hline & Mobile internet & $99(79.8 \%)$ & $25(20.2 \%)$ & 124 & 22.6 \\
\hline & Data card & $123(87.9 \%)$ & $17(12.1 \%)$ & 140 & 25.5 \\
\hline \multirow[t]{2}{*}{ _ogin status } & $\begin{array}{l}\text { Log in and off } \\
\text { occasionally during } \\
\text { the day }\end{array}$ & $360(83.1 \%)$ & $73(16.9 \%)$ & 433 & 79.0 \\
\hline & Permanently online & $106(92.2 \%)$ & $9(7.8 \%)$ & 115 & 21.0 \\
\hline \multirow[t]{2}{*}{ Jurrent Khat chewer } & Yes & $100(96.2 \%)$ & $4(3.8 \%)$ & 104 & 19.0 \\
\hline & No & $366(82.4 \%)$ & 78(17.6\%) & 444 & 81.0 \\
\hline \multirow{2}{*}{$\begin{array}{l}\text { Jurrent cigarette } \\
\text { smoker }\end{array}$} & Yes & $61(98.4 \%)$ & $1(1.6 \%)$ & 62 & 11.3 \\
\hline & No & $405(83.3 \%)$ & $81(16.7 \%)$ & 486 & 88.7 \\
\hline \multirow{2}{*}{$\begin{array}{l}\text { Jurrent alcohol } \\
\text { Jrunker }\end{array}$} & Yes & $129(92.8 \%)$ & $10(7.2 \%)$ & 139 & 25.4 \\
\hline & No & $337(82.4 \%)$ & $72(17.6 \%)$ & 409 & 74.6 \\
\hline \multirow{2}{*}{$\begin{array}{l}\text { Jurrent cannabis } \\
\text { lse }\end{array}$} & Yes & $22(100.0 \%)$ & $0(0.0 \%)$ & 22 & 4.0 \\
\hline & No & $444(84.4 \%$ & $82(15.6 \%)$ & 526 & 96.0 \\
\hline \multirow[t]{2}{*}{ Mental Distress } & Yes & $101(95.3 \%))$ & $5(4.7 \%)$ & 106 & 19.3 \\
\hline & No & $365(82.6 \%)$ & $77(17.4 \%)$ & 442 & 80.7 \\
\hline
\end{tabular}

\section{Prevalence of Internet addiction}

The frequency of IA was 466 (85\%) of them 305(55.6\%), 153(27.9\%), 8(1.5\%) mild, moderate and severe internet addiction correspondingly. Nevertheless, the remaining $82(15 \%)$ are free from internet addiction (Fig.1).

Participants who login permanently had a greater figure of addiction of the internet than those who log in and off occasionally during the day (92.2\% versus $83.1 \%)$. Those who used the internet for about six months had a greater prevalence of internet addiction than those who used greater than twelve months $(91.6 \%$ versus $84.1 \%$ ) (Table 2 ). 


\section{Table 2: Multivariable analysis of factors related to Internet addiction among Wollo University students Northeast, Ethiopia, $2019(\mathrm{n}=548)$}




\begin{tabular}{|c|c|c|c|c|c|c|}
\hline \multirow{2}{*}{\multicolumn{2}{|c|}{ Variables }} & \multicolumn{2}{|c|}{ Internet addiction } & \multirow[t]{2}{*}{ COR (95\% CI.) } & \multirow{2}{*}{$\begin{array}{l}\text { AOR }(95 \% \\
\text { CI.) }\end{array}$} & \multirow{2}{*}{$\begin{array}{c}\mathrm{P}- \\
\text { value }\end{array}$} \\
\hline & & Yes; N (\%) & No; N (\%) & & & \\
\hline \multirow{5}{*}{$\begin{array}{l}\text { Frequency of } \\
\text { attending a place of } \\
\text { vorship }\end{array}$} & Daily & $204(83.3 \%)$ & $41(16.7 \%)$ & 1 & 1 & \\
\hline & 2-3 times per week. & $123(85.4 \%)$ & $21(14.6 \%)$ & $1.18(0.67,2.09)$ & & \\
\hline & Once a week. & $58(82.9 \%)$ & $12(17.1 \%)$ & $0.97(0.48,1.97)$ & & \\
\hline & Less than weekly. & $53(89.8 \%)$ & $6(10.2 \%)$ & $1.78(0.72,4.40)$ & & \\
\hline & Never & 28(93.3\%) & $2(6.7 \%)$ & $2.81(0.65,12.28)$ & & \\
\hline \multirow{3}{*}{$\begin{array}{l}\text { nternet use } \\
\text { xperience (in } \\
\text { nonths) }\end{array}$} & 0 to 6 months & $120(91.6 \%)$ & $11(8.4 \%)$ & 1 & 1 & \\
\hline & 6 to 12 months & $76(79.2 \%)$ & $20(20.8 \%)$ & $0.35(0.16,0.77)$ & $\begin{array}{l}0.42(0.18 \\
0.96)\end{array}$ & $0.040 *$ \\
\hline & 12 or more months & $270(84.1 \%)$ & $51(15.9 \%)$ & $0.49(0.24,0.96)$ & $\begin{array}{l}0.48(0.24 \\
0.99)\end{array}$ & $0.046 *$ \\
\hline \multirow{2}{*}{$\begin{array}{l}\text { nternet use per day } \\
\text { in hours) }\end{array}$} & Less than 5 hours & $420(83.8 \%)$ & $81(16.2 \%)$ & 1 & 1 & \\
\hline & $\begin{array}{l}\text { Greater than or equal } \\
\text { to } 5 \text { hours }\end{array}$ & $46(97.9 \%)$ & $1(2.1 \%)$ & $8.87(1.21,65.25)$ & $\begin{array}{l}\text { 10.13(1.33 } \\
77.00)\end{array}$ & $0.025 *$ \\
\hline \multirow[t]{4}{*}{$\begin{array}{l}\text { Most common mode } \\
\text { of Internet access }\end{array}$} & $\mathrm{Wi}-\mathrm{Fi}$ & $230(85.8 \%)$ & $38(14.2 \%)$ & $0.84(0.45,1.54)$ & $\begin{array}{l}0.84(0.44 \\
1.60)\end{array}$ & 0.596 \\
\hline & Broadband & $14(87.5 \%)$ & $2(12.5 \%)$ & $0.97(0.20,4.63)$ & $\begin{array}{l}0.84(0.16 \\
4.35)\end{array}$ & 0.834 \\
\hline & Mobile internet & $99(79.8 \%)$ & $25(20.2 \%)$ & $0.55(0.28,1.07)$ & $\begin{array}{l}0.40(0.20 \\
0.83)\end{array}$ & $0.014 *$ \\
\hline & Data card & $123(87.9 \%)$ & $17(12.1 \%)$ & 1 & 1 & \\
\hline \multirow[t]{2}{*}{ _ogin status } & $\begin{array}{l}\text { Log in and off } \\
\text { occasionally during } \\
\text { the day }\end{array}$ & $360(83.1 \%)$ & $73(16.9 \%)$ & 1 & 1 & \\
\hline & Permanently online & $106(92.2 \%)$ & $9(7.8 \%)$ & $2.39(1.16,4.93)$ & & \\
\hline \multirow{2}{*}{$\begin{array}{l}\text { Jetting into } \\
\text { elationships online }\end{array}$} & Yes & $318(87.1 \%)$ & $47(12.9 \%)$ & $1.60(0.99,2.58)$ & & \\
\hline & No & $148(80.9 \%)$ & $35(19.1 \%)$ & 1 & 1 & \\
\hline \multirow[t]{2}{*}{$\begin{array}{l}\text { Playing mobile } \\
\text { yames }\end{array}$} & Yes & $223(91.4 \%)$ & $21(8.6 \%)$ & $2.67(1.57,4.52)$ & $\begin{array}{l}2.40(1.38 \\
4.18)\end{array}$ & $0.002 *$ \\
\hline & No & $243(79.9 \%)$ & $61(20.1 \%)$ & 1 & 1 & \\
\hline \multirow{2}{*}{$\begin{array}{l}\text { Jownloading music } \\
\text { sr videos }\end{array}$} & Yes & $314(87.2 \%)$ & $46(12.8 \%)$ & $1.62(1.00,2.61)$ & & \\
\hline & No & $152(80.9 \%)$ & $36(19.1 \%)$ & 1 & 1 & \\
\hline \multirow{2}{*}{ Natching videos } & Yes & $281(88.6 \%)$ & $36(11.4 \%)$ & $1.94(1.21,3.12)$ & & \\
\hline & No & $185(80.1 \%)$ & $46(19.9 \%)$ & 1 & 1 & \\
\hline \multirow{2}{*}{$\begin{array}{l}\text { For retrieving sexual } \\
\text { nformation }\end{array}$} & Yes & $112(89.6 \%)$ & $13(10.4 \%)$ & $1.68(0.90,3.15)$ & & \\
\hline & No & $354(83.7 \%)$ & $69(16.3 \%)$ & 1 & 1 & \\
\hline \multirow[t]{2}{*}{ That rooms } & Yes & $228(87.4 \%)$ & $33(12.6 \%)$ & $1.42(0.88,2.29)$ & & \\
\hline & No & $238(82.9 \%)$ & $49(17.1 \%)$ & 1 & 1 & \\
\hline \multirow[t]{2}{*}{ Jurrent Khat chewer } & Yes & $100(96.2 \%)$ & $4(3.8 \%)$ & $5.33(1.90,14.91)$ & $\begin{array}{l}3.34(1.14 \\
9.83)\end{array}$ & $0.028 *$ \\
\hline & No & $366(82.4 \%)$ & $78(17.6 \%)$ & 1 & 1 & \\
\hline \multirow[t]{2}{*}{$\begin{array}{l}\text { Jurrent cigarette } \\
\text {;moker }\end{array}$} & Yes & $61(98.4 \%)$ & $1(1.6 \%)$ & $\begin{array}{l}12.20(1.67 \\
89.28)\end{array}$ & & \\
\hline & No & $405(83.3 \%)$ & $81(16.7 \%)$ & 1 & 1 & \\
\hline \multirow[t]{2}{*}{$\begin{array}{l}\text { Jurrent alcohol } \\
\text { Jrunker }\end{array}$} & Yes & $129(92.8 \%)$ & $10(7.2 \%)$ & $2.76(1.38,5.51)$ & $\begin{array}{l}2.32(1.09 \\
4.92)\end{array}$ & $0.029 *$ \\
\hline & No & $337(82.4 \%)$ & $72(17.6 \%)$ & 1 & 1 & \\
\hline Mental Distress & Yes & $101(95.3 \%)$ & $5(4.7 \%)$ & $4.26(1.68,10.81)$ & $2.69(1.02$ & $0.045^{*}$ \\
\hline & & Page & & & & \\
\hline
\end{tabular}




\section{Reasons for internet use among Wollo University students}

The furthermost frequent reasons for IA among Wollo University undergraduate students were using the internet for courses / assignments (93.6\%), for social networks (Facebook, etc.)(85.6\%), for reading / posting news $(76.6 \%)$, for getting into relationships online $(66.6 \%)$,for playing mobile games( $44.5 \%)$, for downloading music or videos $(65.7 \%)$, for watching videos $(57.8 \%)$,for retrieving sexual information (22.8\%), for chat rooms (47.6\%) and for e-mail ( reading, writing ) (49.8\%) (Fig. 2).

\section{Factors related to internet addiction}

On univariable analysis, internet addiction was associated with using the internet for more than 12 months ( $\mathrm{OR}=0.49 ; \mathrm{Cl}: 0.24-0.96)$. Those who were using the internet for more than 5 hours per day were more likely to develop internet addiction than those who were using less than 5 hours $(\mathrm{OR}=8.87 ; \mathrm{Cl}$ : 1.21 65.25). Mode of internet access was related to internet addiction i.e. those who used mobile internet were $45 \%$ lower risks of having internet addiction than those who used data cards (OR $=0.55 ; 95 \% \mathrm{Cl}$ : 0.28 1.07). Those who were permanently online were most likely to have internet addiction than those who were not (OR=2.39; $95 \% \mathrm{Cl}: 1.16-4.93)$. Study participants who played mobile games online were more likely to develop internet addiction than those who were not played mobile games (OR=2.67; 95\% Cl: 1.57 4.52). Those who downloaded music or videos were higher risks of having internet addiction than those who didn't (OR=1.62; 95\% Cl: 1.00-2.61). Study participants who watched video online were most likely to have internet addiction than those who didn't watch (OR=1.94; 95\% Cl: 1.21-3.12). Those who chewed khat currently were higher odds of having internet addiction than those who were not (OR=5.33;95\% Cl: 1.90-14.91). Those who smoked cigarettes currently were more likely to have internet addiction than their counterparts ( $\mathrm{OR}=12.20 ; 95 \% \mathrm{Cl}: 1.67-89.28)$. Those who used alcohol currently were greater risks of having internet addiction than those who hadn't $(\mathrm{OR}=2.76 ; 95 \% \mathrm{Cl}: 1.38-5.51)$. Study participants who had mental distress were four times more likely to develop internet addiction than those who didn't have mental distress (OR=4.26; 95\% Cl: 1.68-10.81) (Table 2).

In the final model, using the internet greater than five hours daily, having mental distress, playing online games, current khat chewing and current alcohol use were positively related to internet addiction. Using the internet for more than twelve months and using the internet by mobile internet were negatively related with internet addiction (Table 2).

\section{Discussions}


The current study documents a high prevalence of internet addiction among Wollo University students. In the final model, factors independently associated with internet addiction were using the internet greater than five hours daily, having mental distress, playing online games, current khat chewing and current alcohol use.

The prevalence of internet addiction in the present study was higher than the prevalence of internet addiction that was done in different universities such as Malaysian $36.9 \%$ to $81 \%(22,23)$, American medical students $16.8 \%(11)$, American community $25.1 \%$ (24), Iran $40.7 \%(25)$, Japan $63.5 \%(26)$, Greek $12 \%(32)$, Jordan $40 \%$ (16), Lebanon 16.8\% (11), Nepal 35.4\% (17) and north India 25.3\% (19). The discrepancy might be due to the cut-off point of YIAT-20, instrument difference, mental health policy, cultural difference i.e. time utilization, the difference in study participants, sample size and the time difference between the studies. The study in Malaysian University was conducted among medical students only and focusing on mild internet addiction and moderate internet addiction and not on severe internet addiction.

In our study using the internet for more than five hours daily is 10 times more likely to develop internet addiction than those who are using less than five hours. The finding of this study in line with similar studies done on college students in Taiwan (18). The possible explanation for the association between Internet usage time and Internet addiction is that it might be as much a symptom as it is a cause. However, this study design was cross-sectional and no causal relationship can be clarified, further studies ought to examine whether Internet usage time is an essential factor for determining Internet addiction. Likewise, students who had mental distress were 2.7 times more likely to develop internet addiction as compared to their counterparts. Study findings in these areas showed that students who had mental distress were related to higher levels of internet addiction than students who hadn't mental distress (11, $14-16,19,27)$. This could be due to the Khantzian's(33) self-medication hypothesis, indicating that mentally distressed university students might come to rely on the Internet as a method for coping with their mental distress. Hence, they will devote more and more time on the Internet and headway toward addiction if their mental distress symptoms are not cured(34).

Students who had playing online games were 2.4 times higher to have internet addiction than their counterparts. A similar finding was also reported in Greek University(13). Furthermore, students who chewed khat currently were three times most likely to develop internet addiction than students who reported no current khat chewing which is in line with the study finding in Greek University students (13). In this study, students who drank alcohol currently were 2.3 times most likely to have internet addiction as compared with students who didn't drink alcohol.

Other studies reported a similar finding (13). Probable reasons involve either common forerunner factors that encourage liability to the co-occurrence between drug use or the existence of other personal habits/dependencies and internet addiction, and that they represent different conditions along a spectrum of related disorders of addiction. Nevertheless, susceptibility factors relating to internet addiction and substance use disorders persist obscure. This coexistence of internet addiction with other 
personal habits/dependencies is a similar pattern to that observed in the coexistence of pathological gambling and substance abuse. Though this comparison might be unequal, it is valuable to pull upon it as an example, to pursue aetiological factors(35).

Students who used the internet by mobile internet were $60 \%$ of lower risks of having internet addiction as compared to those students who used data cards. This might be due to inadequate finance to use the internet on mobile internet. So, the students may refrain from using the internet through mobile internet. Students who used the internet for more than 12 months were $52 \%$ less likely to have internet addiction than their counterparts. The current finding is not supported by other studies in the world.

\section{Conclusions}

The current study documents a high prevalence of internet addiction among Wollo University students. Factors independently associated with internet addiction were using the internet greater than five hours daily, having mental distress, playing online games, current khat chewing and current alcohol use. So, we advise that Wollo University should establish prevention programs focus on educating students about emotional regulation skills and the harmful effects of substance use to minimize internet addiction.

\section{Abbreviations}

ADHD: Attention deficit hyperactivity disorder; CGPA: Cumulative grade point average; Cl: Confidence interval; DSM_V: Diagnostic and statistical manual fifth edition; IA: Internet addiction; PIU: Problematic internet use; SPSS: Statistical package for social science; YIAT: Young's internet addiction test.

\section{Declarations}

\section{Ethics approval and consent to participate}

The study was conducted after getting ethical clearance from Wollo University College of medicine and health science institutional review board. A formal letter of permission was obtained from the student service directorate of Wollo University. The respondents were informed about the aim of the study. Confidentiality and privacy of the respondents were maintained. Written consent was obtained from each participant before administering the questionnaire.

\section{Consent for publication}

Not applicable

\section{Availability of data and materials}


The dataset supporting the conclusions of this article is available with the corresponding author and will be made available on reasonable request.

\section{Competing interests}

The authors report no conflicts of interest in this work

\section{Funding}

Not applicable

\section{Authors' contributions}

YZ and KK designed and supervised the study, carried out the analysis, and interpreted the data; $M$ M, $A B$, MB, MNA, MS, MT and BA assisted in the design, analysis, and interpretation of the data; and YZ wrote the manuscript. All authors contributed toward data analysis, drafting and critically revising the paper and agree to be accountable for all aspects of the work.

\section{Acknowledgments}

We thank the Department of Psychiatry, College of Medicine and Health Sciences, Wollo University for supporting the research in different ways. We extend our heartfelt thanks to the student service directorate office for providing us the necessary information. We are grateful to all the students who participated in the study. Finally, we would like to thank Mr. Sisay Eshetie for his assistance in preparing table and figure legends.

\section{References}

1. World wide web foundation. Internet users in the world. . 1, March, 2018.

2. Bremer J. The internet and children: advantages and disadvantages. Child and Adolescent Psychiatric Clinics. 2005;14(3):405-28.

3. Swaminath G. Internet addiction disorder: fact or fad? Nosing into nosology. Indian journal of Psychiatry. 2008;50(3):158.

4. Dargahi H, Razavi S. Internet addiction and its related factors: A study of an Iranian population. 2007.

5. Kuss DJ, Griffiths MD. Online social networking and addiction-a review of the psychological literature. International journal of environmental research and public health. 2011;8(9):3528-52.

6. Pfaff DW, Volkow ND. Neuroscience in the 21st century: from basic to clinical: Springer; 2016. 
7. Panicker J, Sachdev R. Relations among loneliness, depression, anxiety, stress and problematic internet use. International Journal of Research in Applied, Natural and Social Sciences. 2014;2(9):110.

8. Xiuqin H HZ, Mengchen L, Jinan W, Ying Z, Ran T. . Mental health, personality, and parental rearing styles of adolescents with Internet addiction disorder. . Cyberpsychol Behav Soc Netw 2010;13(4):401-6.

9. Alavi SS AH, Maracy MR, Jannatifard F, Eslami M, Ferdosi M. Impact of addiction to internet on a number of psychiatric symptoms in students of Isfahan universities, Iran. Int J Prev Med 2012;3; (2):122-7.

10. Kandell JJ. Internet addiction on campus: The vulnerability of college students. Cyberpsychology \& behavior. 1998;1(1):11-7.

11. Younes F, Halawi G, Jabbour H, El Osta N, Karam L, Hajj A, et al. Internet addiction and relationships with insomnia, anxiety, depression, stress and self-esteem in university students: A cross-sectional designed study. PloS one. 2016;11(9):e0161126.

12. Krishnamurthy S, Chetlapalli SK. Internet addiction: Prevalence and risk factors: A cross-sectional study among college students in Bengaluru, the Silicon Valley of India. Indian journal of public health. 2015;59(2):115.

13. Frangos CC, Frangos CC, Sotiropoulos I. Problematic internet use among Greek university students: an ordinal logistic regression with risk factors of negative psychological beliefs, pornographic sites, and online games. Cyberpsychology, Behavior, and Social Networking. 2011;14(1-2):51-8.

14. Gedam SR, Ghosh S, Modi L, Goyal A, Mansharamani H. Study of internet addiction: Prevalence, pattern, and psychopathology among health professional undergraduates. Indian Journal of Social Psychiatry. 2017;33(4):305.

15. Kitazawa M, Yoshimura M, Murata M, Sato-Fujimoto $Y$, Hitokoto H, Mimura M, et al. Associations between problematic Internet use and psychiatric symptoms among university students in Japan. Psychiatry and clinical neurosciences. 2018;72(7):531-9.

16. Al-Gamal E, Alzayyat A, Ahmad MM. Prevalence of I nternet Addiction and Its Association With Psychological Distress and Coping Strategies Among University Students in J ordan. Perspectives in psychiatric care. 2016;52(1):49-61.

17. Bhandari PM, Neupane D, Rijal S, Thapa K, Mishra SR, Poudyal AK. Sleep quality, internet addiction and depressive symptoms among undergraduate students in Nepal. BMC psychiatry. 2017;17(1):106.

18. Lin M-P, Ko H-C, Wu JY-W. Prevalence and psychosocial risk factors associated with Internet addiction in a nationally representative sample of college students in Taiwan. Cyberpsychology, Behavior, and Social Networking. 2011;14(12):741-6.

19. Gupta A, Khan AM, Rajoura O, Srivastava S. Internet addiction and its mental health correlates among undergraduate college students of a university in North India. Journal of family medicine and primary care. 2018;7(4):721. 
20. Chou C, Hsiao M-C. Internet addiction, usage, gratification, and pleasure experience: the Taiwan college students' case. Computers \& Education. 2000;35(1):65-80.

21. Yang T, Yu L, Oliffe JL, Jiang S, Si Q. Regional contextual determinants of internet addiction among college students: a representative nationwide study of China. The European Journal of Public Health. 2017;27(6):1032-7.

22. Ching SM, Awang H, Ramachandran V, Lim S, Sulaiman W, Foo Y, et al. Prevalence and factors associated with internet addiction among medical students-A cross-sectional study in Malaysia. Med J Malaysia. 2017;72(1):7-11.

23. Haque M, Rahman NAA, Majumder MAA, Haque SZ, Kamal ZM, Islam Z, et al. Internet use and addiction among medical students of Universiti Sultan Zainal Abidin, Malaysia. Psychology research and behavior management. 2016;9:297.

24. Jelenchick LA, Becker T, Moreno MA. Assessing the psychometric properties of the Internet Addiction Test (IAT) in US college students. Psychiatry research. 2012;196(2-3):296-301.

25. Bahrainian SA, Alizadeh KH, Raeisoon M, Gorji OH, Khazaee A. Relationship of Internet addiction with self-esteem and depression in university students. Journal of preventive medicine and hygiene. 2014;55(3):86.

26. Tateno M, Teo AR, Shirasaka T, Tayama M, Watabe M, Kato TA. Internet addiction and self-evaluated attention-deficit hyperactivity disorder traits among Japanese college students. Psychiatry and clinical neurosciences. 2016;70(12):567-72.

27. Seyrek S, Cop E, Sinir H, Ugurlu M, Şenel S. Factors associated with Internet addiction: Crosssectional study of Turkish adolescents. Pediatrics international. 2017;59(2):218-22.

28. Young KS. Internet addiction: The emergence of a new clinical disorder. Cyberpsychology \& behavior. 1998;1(3):237-44.

29. Frangos CC, Frangos CC, Sotiropoulos I, editors. A meta-analysis of the reliabilty of young's internet addiction test. Proceedings of the World Congress on Engineering; 2012: World Congress on Engineering London, United Kingdom.

30. Kessler RC, Barker PR, Colpe LJ, Epstein JF, Gfroerer JC, Hiripi E, et al. Screening for serious mental illness in the general population. Archives of general psychiatry. 2003;60(2):184-9.

31. Andrews G, Slade T. Interpreting scores on the Kessler psychological distress scale (K10). Australian and New Zealand journal of public health. 2001;25(6):494-7.

32. Frangos CC FC, Sotiropoulos I. A meta-analysis of the reliability of young's internet addiction test. . A meta-analysis of the reliability of young's internet addiction test. WCE. 2012;1:368-71.

33. Khantzian EJ. The self-medication hypothesis of substance use disorders: A reconsideration and recent applications. Harvard review of psychiatry. 1997;4(5):231-44.

34. Yen J-Y, Ko C-H, Yen C-F, Wu H-Y, Yang M-J. The comorbid psychiatric symptoms of Internet addiction: attention deficit and hyperactivity disorder (ADHD), depression, social phobia, and hostility. Journal of adolescent health. 2007;41(1):93-8. 
35. Hall GW, Carriero NJ, Takushi RY, Montoya ID, Preston KL, Gorelick DA. Pathological gambling among cocaine-dependent outpatients. American Journal of psychiatry. 2000;157(7):1127-33.

\section{Figures}

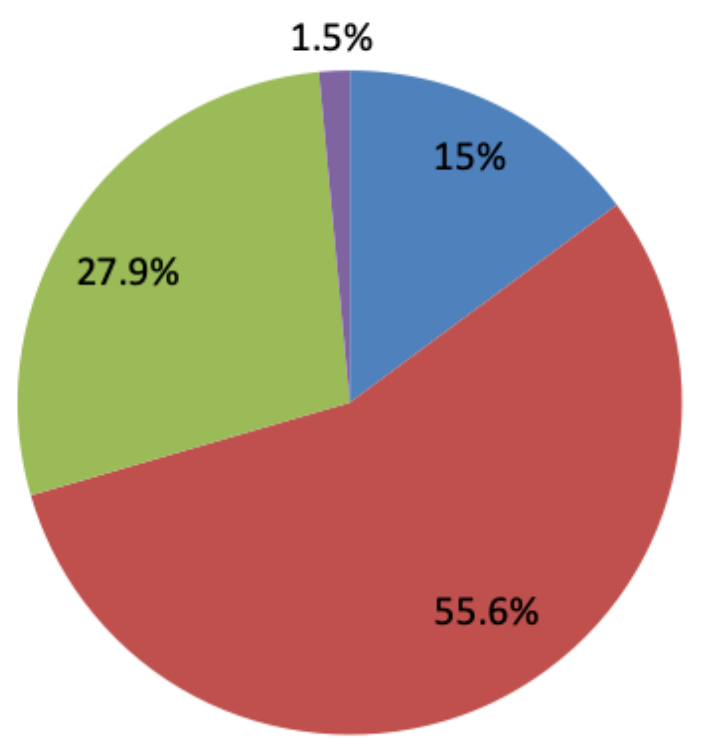

Normal

Mild

Moderate

Severe

\section{Figure 1}

Internet addiction by severity among Wollo University students Northeast, Ethiopia, 2019 ( $n=548)$ 


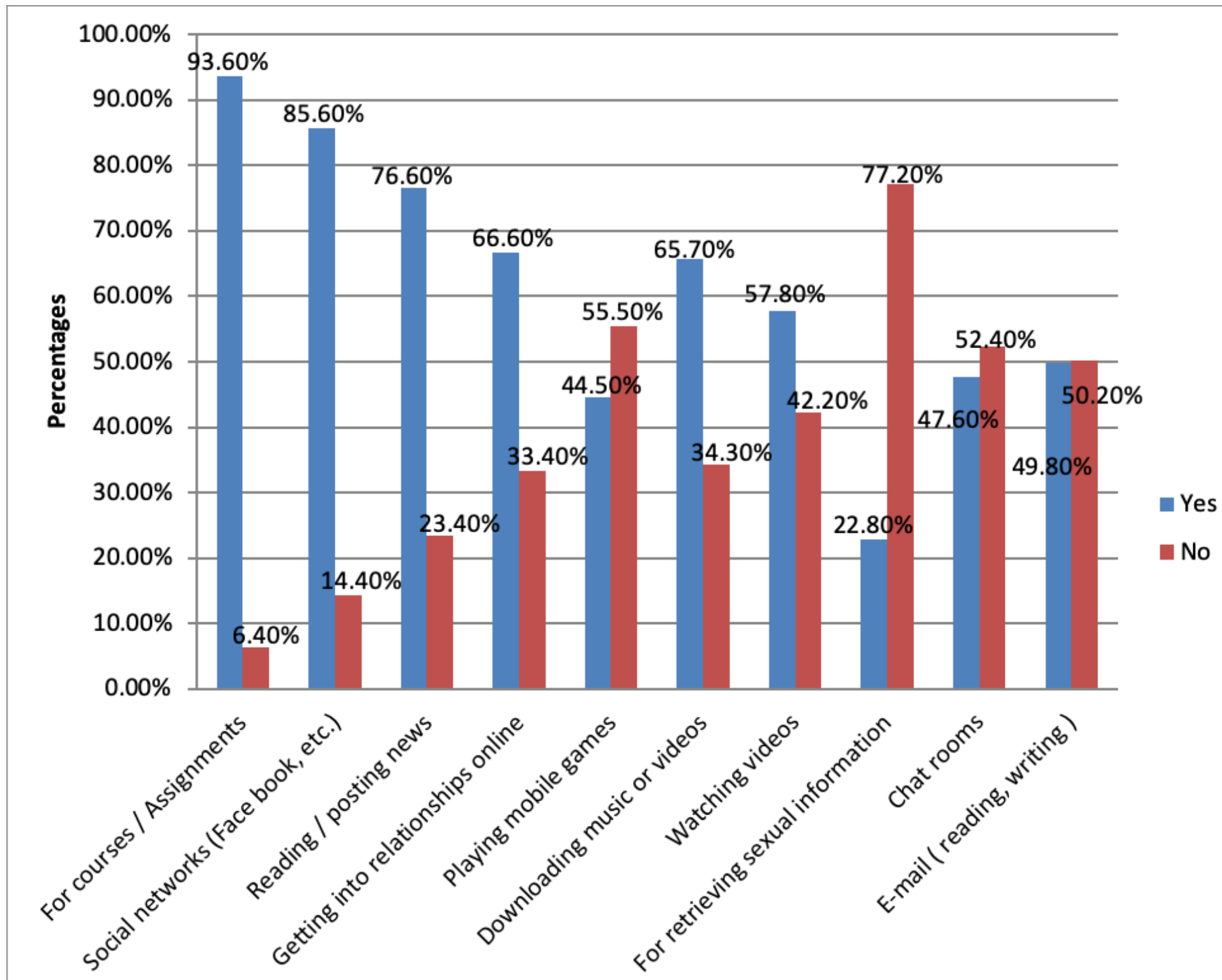

Reasons for internet use

Figure 2

Reasons for internet use among Wollo University students Northeast, Ethiopia, 2019 ( $n=548)$ 